\title{
LAS LÓGICAS DEÓNTICAS DE GEORG H. VON WRIGHT
}

Carlos Alarcón Cabrera

Universidad de Huelva

\section{Los presupuestos de la lógica deóntica}

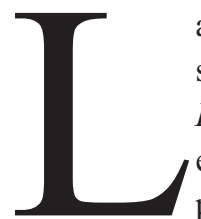

a expresión "Lógica Deóntica" fue usada por primera vez con su significado actual en 1951, en el conocido artículo Deontic Logic publicado en la revista Mind por Georg H. von Wright, ilidad, contingencia; conceptos estudiados por la lógica modal), a los conceptos modales existenciales (universalidad, existencia, vaciedad; conceptos estudiados por la teoría de la cuantificación) y a los conceptos modales epistémicos (lo verificado, lo indeterminado, lo falsado), von Wright introdujo los conceptos modales deónticos: lo obligatorio, lo permitido, lo prohibido (von Wright, 1951). Desde entonces, el término "deóntico" ha ido haciéndose común en el léxico filosófico. En particular, como resalta Mazzarese, con una acepción pragmática y con una acepción semántica: a) Pragmáticamente, como sinónimo de 'directivo', 'preceptivo', 'prescriptivo', 'normativo', en oposición a 'descriptivo', 'declarativo', 'asertivo'; b) Semánticamente, en el sentido de "concerniente al deber ser", para designar lo que constituye la esfera del deber ser o lo que describe la esfera del deber ser (Mazzarese, 1989).

Sin embargo, en su artículo de 1951 von Wright no dio una respuesta explícita a una cuestión muy debatida en los anteriores años en el ámbito filosófico escandinavo, estrechamente relacionada con la propia razón de ser y sentido de la lógica deóntica, que desde entonces se conoce como el dilema de Jorgensen, y que podría resumirse así (vid. Jorgensen, 1938):

Por una parte, se considera tradicionalmente que la lógica se rige por los valores "verdadero" y "falso". Inferir lógicamente una proposición de otra significa que, si una de ellas es verdadera, la otra también lo es; $y$, sucesivamente, una secuencia de proposiciones forma un raciocinio lógico si todas ellas son verdaderas. Esta condición no se cumple en las proposiciones no 
descriptivas, y en particular en proposiciones prescriptivas como las normas jurídicas, que no pueden asumir el valor lógico "verdad", que no son ni verdaderas ni falsas, por lo que no es posible construir razonamientos lógicos con ellas, no es posible que las inferencias lógicas contengan premisas que sean prescriptivas, y por tanto no descriptivas.

Sin embargo, por otra parte, y esto es lo que convierte la tesis de Jorgensen en dilemática, parece evidente la posibilidad de construir inferencias lógicas que incluyan prescripciones prescriptivas. Por ejemplo:

Está prohibido fumar en las Facultades universitarias

La Facultad de Derecho es una Facultad universitaria

Está prohibido fumar en la Facultad de Derecho

Aparentemente, esta inferencia es tan valida como cualquier otra construida exclusivamente con proposiciones descriptivas, como por ejemplo:

Los jugadores del Real Madrid visten de blanco

Butragueño es jugador del Real Madrid

Butragueño viste de blanco

La premisa mayor y la conclusión de la primera de las dos inferencias ("Está prohibido fumar en las Facultades universitarias" y "Está prohibido fumar en la Facultad de Derecho", respectivamente) están prescribiendo, a diferencia de las premisas de la segunda inferencia, que están describiendo. Pero ello no parece impedir la validez de la primera inferencia.

Así planteados, los dos cuernos del dilema de Jorgensen son paradójicamente consistentes, y parecen chocar alrededor del problema de si la verdad es el único valor lógico, de si de las premisas lógicas puede predicarse algún otro valor alternativo a la verdad (ya que, a diferencia de las descripciones "Los jugadores del Real Madrid visten de blanco", "Butragueño es jugador del Real Madrid" y "Butragueño viste de blanco", que son verdaderas o falsas, las prescripciones "Está prohibido fumar en las Facultades universitarias" y "Está prohibido fumar en la Facultad de Derecho" no son ni verdaderas ni falsas). La función de la lógica ha consistido tradicionalmente en la atribución de valor de verdad a expresiones moleculares a partir del valor de verdad de las expresiones atómicas constituyentes. Esta producción de conclusiones verdaderas debe sistematizarse y ajustarse a ciertos tipos de métodos, para lo cual se utilizan los principios lógicos que regulan los cálculos inferenciales. Ahora bien, ¿es la verdad el único valor lógico? En el caso de proposiciones no descriptivas, ¿no son posibles otros valores lógicos?

Para Kalinowski, como para muchos de los que aceptan el segundo cuerno del dilema de Jorgensen (y por consiguiente la posibilidad de construir inferencias lógicas con normas, la posibilidad de una lógica de las normas), incluso sin apartarnos de la lógica bivalente no es preciso aferrarnos a los valores de verdad y falsedad como los únicos posibles. El error que habría 
motivado la creencia en una única pareja de valores lógicos era para Kalinowski la inexacta distinción entre dos acepciones del término "proposición”, según se entendiera en sentido gramatical o en sentido lógico. Conforme a esta distinción, las proposiciones gramaticales englobarían todas las expresiones con estructura sintáctica proposicional (no sólo descripciones, sino también prescripciones, deseos, preguntas, consejos,...), mientras que las proposiciones lógicas serían un subtipo de las proposiciones gramaticales: las significativas de juicios verdaderos o falsos. Kalinowki rechaza esta diferenciación porque toda proposición gramatical es en potencia lógica, con lo que no hay distinción material sino en todo caso metodológica: desde un punto de vista gramatical las proposiciones se estudian por la lingüística, en particular por la sintáctica, y desde un punto de vista lógico las proposiciones se estudian por la lógica y por la metalógica. Toda proposición gramatical podría, independientemente de su estructura sintáctica, ser una proposición lógica aunque no fuera verificable. Verdad y falsedad serían valores lógicos relativos a las proposiciones descriptivas, pero no agotarían el terreno de actuación de la lógica (Kalinowski, 1972). Como también indicó Klug, el problema de la aplicación de los principios lógicos a las normas sería un simple problema semántico que se podría resolver reinterpretando los fundamentos de la lógica, sin que fuera imprescindible que los principios lógicos se aplicaran sólo a enunciados verdaderos o falsos (Klug, 1951).

\subsection{La lógica del cumplimiento normativo}

Transformemos una norma convirtiéndola en una proposición sobre lo que la norma exige de sus destinatarios. Convirtamos la norma "Está prohibido fumar en los centros públicos" en: "La norma exige el comportamiento que se puede describir así: "No se fuma en los centros públicos"”; o, de forma simplificada, en: "No se fuma en los centros públicos". De esta última proposición podemos deducir la proposición "No se fuma en los hospitales", que sería la formulación en términos de cumplimiento de la norma "Está prohibido fumar en los hospitales". Mediante el recurso al valor del cumplimiento o satisfacción normativa, hemos inferido, aparentemente, una norma ("Está prohibido fumar en los hospitales") de otra norma ("Está prohibido fumar en los centros públicos").

Podría entonces parecer que es posible usar el valor del cumplimiento respecto a las relaciones lógicas entre las normas de modo semejante al uso del valor de la verdad respecto a las relaciones lógicas entre las proposiciones descriptivas. De la misma forma que, de dos proposiciones descriptivas contradictorias (por ejemplo: "Llueve" y "No llueve"), sólo una puede ser verdadera, de dos normas contradictorias (por ejemplo: "Se debe conducir por la derecha" y "No se puede conducir por la derecha"), sólo una podría 
ser cumplida. Igual que la verdad o falsedad de la proposición descriptiva, también el cumplimiento o incumplimiento de la norma dependería de circunstancias externas a la norma misma, y en particular de la conducta de sus destinatarios.

Sin embargo, como insistentemente resaltarían después Kelsen y el propio von Wright, dos normas incompatibles de un mismo ordenamiento podrían ser aplicadas a la vez por dos jueces diferentes, mientras que dos proposiciones descriptivas contradictorias nunca pueden ser simultáneamente verdaderas (Kelsen, 1965). La cuestión es si realmente el valor del cumplimiento es respecto a las normas una alternativa al valor lógico de la verdad. Para saber si una norma se cumple o se incumple debemos verificar empíricamente cuál es el comportamiento de sus destinatarios, es necesario utilizar de nuevo categorías veritativas, comprobar si es verdad o no que se realiza el comportamiento prescrito, por lo que en realidad seguimos moviéndonos alrededor del valor lógico de la verdad. El cumplimiento o satisfacción de las normas no es en sí mismo un valor lógico alternativo.

\subsection{La lógica de la validez}

La ineficacia de la solución a la que acabamos de referirnos indujo a Alf Ross a reflexionar en un trabajo con el mismo título que el de Jorgensen (Imperativos y lógica, 1941) sobre otra solución más natural: utilizar la validez como criterio lógico de relación entre las normas, para así derivar conclusiones normativas válidas de premisas normativas válidas (por ejemplo, derivar la validez de "Prohibido fumar en los hospitales" de la validez de "Prohibido fumar en los centros públicos"). Ross hablaba de validez de las normas rechazando su sentido objetivo, sentido que exigiría constatar la existencia de un procedimiento de verificación, con lo que se volvería a acudir indirectamente al valor de la verdad a través de una ética normativa científica, que Ross descartaba "porque sólo ocupa un sitio en el desván de la metafísica moral y religiosa". Las normas son válidas en sentido subjetivo, como "presencia en la autoridad normativa de un estado psicológico que determina la validez de la norma". Pero, justamente por esta concepción subjetiva y psicológica de la validez normativa, el primer Ross no concebía inferencias normativas que no fueran "pseudológicas", que no presupusieran la coherencia de la voluntad del legislador (Ross, 1941).

En esta misma línea, von Wright, al criticar la analogía entre la verdad de las proposiciones descriptivas y la validez de las normas, subrayó el hecho de que una norma siempre es válida en relación con otra norma que permite su promulgación, pero no es exacto decir que el fundamento de la validez de una norma se encuentra en la validez de otra norma. La norma inferior no "obtiene" su validez por la validez de la norma superior, sino por la exis- 
tencia de ésta en un lugar en el que mantiene una relación jerárquica con la primera. Si no fuera así nos enfrentaríamos a una remisión al infinito, ya que toda norma requeriría otra norma superior. Por su parte, la verdad de una proposición sí se "obtiene" de la verdad de otra proposición (von Wright, 1963; cfr. Alchourrón / Bulygin, 1991).

\subsection{La verdad como valor normativo}

La segunda forma de negar el argumento según el cual no existen relaciones lógico-deductivas entre las normas es más directa. Consiste en considerar que de las normas sí se puede predicar la verdad o la falsedad, que las normas son verdaderas o falsas, que son entidades apofánticas.

La naturaleza apofántica de las normas ha sido defendida particularmente por Kalinowski basándose en la definición de proposición verdadera de Tarski: "La proposición 'p' es verdadera si, y solamente si, p". Aplicada a las normas, "la norma 'n' es verdadera si, y solamente si, n”. Por ejemplo, la norma "El hombre no debe cometer homicidio" es verdadera si y sólo si el hombre no debe cometer homicidio. Del mismo modo que un enunciado descriptivo es verdadero si se corresponde con su objeto (el enunciado "Llueve" es verdadero si, en la realidad externa, llueve), un enunciado prescriptivo o deóntico también es verdadero si se corresponde con su objeto, con su "status deóntico". La norma "El hombre no debe cometer homicidio" es incondicionalmente verdadera si existe el status deóntico "El hombre no debe cometer homicidio"; si, conforme a la "realidad deóntica", $\mathrm{y}$ anterior e independientemente de que lo establezca el derecho positivo correspondiente, el hombre no debe cometer homicidio, cuestión que se responde afirmativamente desde el iusnaturalismo y negativamente desde el positivismo jurídico. Como el propio Kalinowski reconoce, éste es un problema que provoca la discusión sobre el carácter racional o irracional de la moral por sus referencias metafísicas. Hablar de "norma verdadera" exige "creer en la derivación de las normas positivas respecto al derecho natural, que a su vez se deduce de la ley eterna divina, de la que se desprende la verdad de determinados enunciados analíticamente evidentes" (Kalinowski, 1967, p. 243).

Incluso en el ámbito teórico del cognoscitivismo ético, la tesis de Kalinowski ha sido muy criticada, en especial en base a que la (supuesta) validez objetiva de las normas no implica su naturaleza veritativa. No sería la norma objetivamente válida, sino la proposición que la describiera, la que sería verdadera. La proposición “'El hombre no debe cometer homicidio' es verdadero si y solamente si el hombre no debe cometer homicidio", reflejo del concepto semántico de verdad, no contiene una norma sino su descripción metalingüística, como lo demuestra el hecho de que una expresión semico- 
millada ("'El hombre no debe cometer homicidio"”) no puede poseer fuerza prescriptiva. Para prescribir, un enunciado ha de usarse (lingüísticamente), no basta con hacer referencia a él, no basta con mencionarse (metalingüisticamente). Lo verdadero o falso no es la norma, sino la mención descriptiva y metalingüística de la norma (Vid. particularmente von Wright, 2001, pp. 391 ss.).

\section{El sistema standard de lógica deóntica (SDL)}

En su trabajo de 1951 Deontic Logic, von Wright construye por primera vez una lógica formal elemental de las modalidades deónticas (obligatorio, permitido, prohibido), una lógica deóntica cuyos presupuestos son los siguientes: $1^{\circ}$ ) Las cosas a las que llamamos obligatorias, permitidas o prohibidas son actos, entendidos no en sentido individual, sino como propiedad que lo califica (robo, pago de impuestos, conducción de un vehículo,...); $2^{\circ}$ ) Respecto a quien realiza el acto (el agente), hay un valor de ejecución del acto y un valor de no ejecución del acto, análogos a los valores clásicos de la verdad y la falsedad.

En este sistema, las variables y las constantes también son análogas a las de la lógica proposicional ordinaria. Respecto a las variables, la única diferencia consiste en que a la letra minúscula ( $\mathrm{p}, \mathrm{q}, \mathrm{r}, \ldots$ ) le precede una de estas dos letras mayúsculas: "O”, que representa la obligación (“Op": "Obligatorio...", "Debes..."), o "P”, que representa la permisión, equivalente a la no prohibición ("Pp": "Permitido...", "Puedes...", o lo que es lo mismo, "No prohibido...", "No es el caso que debas...."). Destaca así la interdefinibilidad de los operadores deónticos: "P" se puede definir como permisión y también como no obligación del comportamiento opuesto ("Pp" equivale a “-O-p". Por ejemplo, "está permitido fumar" equivale a "no es obligatorio no fumar"), y "O" se puede definir como obligación y también como no permisión del comportamiento opuesto (“Op” equivale “-P-p”. Por ejemplo, "es obligatorio pagar el impuesto de la renta" equivale a "no está permitido no pagar el impuesto de la renta").

Para las constantes o conectivas, von Wright utiliza los mismos signos que en la lógica ordinaria, atribuyéndoles el correlativo significado deóntico:

“-“: Negación deóntica. Se lee "no" o "no es el caso que”. Por ejemplo, "-Op" puede significar "no es obligatorio votar" o "no es el caso que sea obligatorio votar". "-Pp" puede significar "no está permitido fumar" o "no es el caso que esté permitido fumar".

“^” o "\&”: Conjunción deóntica. Se lee “y”. Por ejemplo, la conjunción interna “O(p \& q)" puede significar "es obligatorio votar y hacer el servicio militar" o "es el caso que sea obligatorio votar y hacer el servicio militar". 
"P(p \& q)" puede significar "está permitido fumar y tirar las colillas al suelo" o "es el caso que está permitido fumar y tirar las colillas al suelo". Cuando la conjunción es externa, “Op \& Oq” puede por ejemplo significar "es obligatorio votar y es obligatorio hacer el servicio militar" o "es el caso que sea obligatorio votar y sea obligatorio hacer el servicio militar". "Pp \& Pq" puede significar "está permitido fumar y está permitido tirar las colillas al suelo" o "es el caso que está permitido fumar y está permitido tirar las colillas al suelo". Con posterioridad nos referiremos a las implicaciones y coimplicaciones entre la conjunción interna y la conjunción externa.

"v": Disyunción deóntica. Se lee “o". Por ejemplo, la disyunción interna "O(p v q)" puede significar "es obligatorio votar o hacer el servicio militar" o "es el caso que sea obligatorio votar o hacer el servicio militar". "P(p v q)" puede significar "está permitido fumar o tirar las colillas al suelo" o "es el caso que está permitido fumar o tirar las colillas al suelo". Cuando la disyunción es externa, Op v Oq puede por ejemplo significar "es obligatorio votar o es obligatorio hacer el servicio militar" o "es el caso que sea obligatorio votar o sea obligatorio hacer el servicio militar". "Pp v Pq" puede significar "está permitido fumar o está permitido tirar las colillas al suelo" o "es el caso que está permitido fumar o está permitido tirar las colillas al suelo". Con posterioridad nos referiremos a las implicaciones y coimplicaciones entre la disyunción interna y la disyunción externa, que aparenta ser intrínsecamente ambigua. Anticipo que la analogía con la lógica descriptiva ordinaria comienza también a fallar porque " $p$ v q" incluye la posibilidad de que sean ambas, "p" y "q", mientras que parece contraintuitivo que " $\mathrm{P}(\mathrm{p}$ v q)" incluya la posibilidad de que sea "Pp" y sea también "Pq".

“↔”: Coimplicación deóntica o equivalencia deóntica. Se lee "si y sólo si... entonces". Por ejemplo, "Op $\leftrightarrow$ Oq" puede significar "si y sólo si es obligario votar, entonces es obligatorio realizar el servicio militar", o lo que es lo mismo, "si y sólo si es obligatorio realizar el servicio militar, entonces es obligatorio votar". "Pp $\leftrightarrow$ Pq" puede significar "si y sólo si está permitido fumar, entonces está permitido toser", o lo que es lo mismo, "si y sólo si está permitido toser, entonces está permitido fumar".

“ $\rightarrow$ ": Implicación deóntica o condicional deóntico. Se lee "si... entonces". Por ejemplo, "O $(p \rightarrow q)$ " puede significar "es obligatorio que, si nieva, se usen cadenas para las ruedas del coche". " $\mathrm{P}(\mathrm{p} \rightarrow \mathrm{q})$ " puede significar "está permitido que, si el examen dura más de dos horas, se fume". La interpretación deóntica de la implicación es, como se comprobará posteriormente, bastante problemática, en particular porque para evitar que colisione con el concepto de norma hipotética provoca importantes paradojas.

A las reglas básicas de inferencia de la lógica proposicional ordinaria, von Wright añade en el SDL otras específicamente deónticas; en concreto, 
dos reglas sobre la interdefinibilidad, cuatro reglas para la distribución de los operadores deónticos y seis reglas (reconducibles a tres) a las que denomina "leyes sobre el compromiso".

A) Reglas sobre la interdefinibilidad:

$\left.1^{\mathrm{a}}\right) \mathrm{OA} \rightarrow$ PA.

Si debemos hacer "p", nos está permitido hacer "p". Por ejemplo, si debemos pagar impuestos, está permitido pagar impuestos.

$\left.2^{\mathrm{a}}\right) \mathrm{PA} \leftrightarrow-\mathrm{O}-\mathrm{A}$.

Si nos está permitido hacer "p", entonces no es el caso que debemos hacer "-p", e, inversamente, si no debemos hacer "-p", entonces nos está permitido hacer "p". Por ejemplo, si nos está permitido fumar, entonces no es obligatorio no fumar, e, inversamente, si no es obligatorio no fumar, entonces nos está permitido fumar.

B) Reglas para la distribución de los operadores deónticos:

$\left.3^{\mathrm{a}}\right) \mathrm{O}(\mathrm{A} \& \mathrm{~B}) \leftrightarrow \mathrm{OA} \& \mathrm{OB}$.

Si es obligatorio hacer "p" y "q", entonces es obligatorio hacer "p" y hacer "q", e, inversamente, si es obligatorio hacer "p" y hacer "q", entonces es obligatorio hacer "p" y "q". Por ejemplo, si es obligatorio hacer el servicio militar y pagar impuestos, entonces es obligatorio hacer el servicio militar y es obligatorio pagar impuestos, e, inversamente, si es obligatorio hacer el servicio militar y es obligatorio pagar impuestos, entonces es obligatorio hacer el servicio militar y pagar impuestos.

$\left.4^{\mathrm{a}}\right) \mathrm{P}(\mathrm{A} \vee \mathrm{B}) \leftrightarrow \mathrm{PA} \vee \mathrm{PB}$.

Si está permitido hacer o "p" o "q", entonces está permitido hacer " $p$ " o está permitido hacer "q", e, inversamente, si está permitido hacer "p" o está permitido hacer "q", entonces está permitido hacer o "p" o "q". Von Wright no parece del todo consciente de la ambigüedad de la permisión deóntica disyuntiva. Decir, por ejemplo, que si está permitido o fumar o conducir, entonces está permitido fumar o está permitido conducir, e, inversamente, si está permitido fumar o está permitido conducir, entonces está permitido o fumar o conducir, resulta contraintuitivo porque no queda claro si es o no el agente quien decide cuál de los dos actos está permitido.

$\left.5^{\mathrm{a}}\right) \mathrm{OA} \vee \mathrm{OB} \rightarrow \mathrm{O}(\mathrm{A} \vee \mathrm{B})$

Si es obligatorio hacer "p" u obligatorio hacer "q", entonces es obligatorio hacer o "p" o "q". Esta fórmula provoca problemas similares a la anterior. Tampoco queda claro si es el agente quien decide cuál de los dos actos es obligatorio si afirmamos que si es obligatorio pagar impuestos o es obligatorio votar, entonces es obligatorio o pagar los impuestos o votar.

$\left.6^{\mathrm{a}}\right) \mathrm{P}(\mathrm{A} \& \mathrm{~B}) \rightarrow \mathrm{PA} \& \mathrm{~PB}$ 
Si está permitido hacer "p" y "q", entonces está permitido hacer "p" y está permitido hacer "q". Por ejemplo, si está permitido fumar y conducir, entonces está permitido fumar y está permitido conducir.

C) Leyes sobre el compromiso:

$\left.7^{\mathrm{a}}\right) \mathrm{OA} \& \mathrm{O}(\mathrm{A} \rightarrow \mathrm{B}) \rightarrow \mathrm{OB}$

Von Wright la considera una tautología deóntica: si es obligatorio hacer "p", y si hacer "p" nos compromete a hacer "q", entonces es obligatorio hacer "q".

$\left.8^{\mathrm{a}}\right) \mathrm{PA} \& \mathrm{O}(\mathrm{A} \rightarrow \mathrm{B}) \rightarrow \mathrm{PB}$

Si está permitido hacer "p", y si hacer "p" nos compromete a hacer "q", entonces está permitido hacer "q".

$\left.9^{\mathrm{a}}\right)-\mathrm{PB} \& \mathrm{O}(\mathrm{A} \rightarrow \mathrm{B}) \rightarrow-\mathrm{PA}$

Si no está permitido hacer "q", y si hacer "p" nos compromete a hacer “q", entonces no está permitido hacer "p".

Como el propio von Wright resaltará posteriormente, la naturaleza paradójica de la fórmula del compromiso $\mathrm{O}(\mathrm{A} \rightarrow \mathrm{B})$ se puede demostrar si partimos de una de las bases axiomáticas del SDL, la regla distributiva $4^{\mathrm{a}}$ ) ya citada

$\mathrm{P}(\mathrm{A} \vee \mathrm{B}) \leftrightarrow \mathrm{PA} \vee \mathrm{PB}$

Teniendo en cuenta la interdefinibilidad de los operadores deónticos, esta regla es equivalente a

$\mathrm{O}(\mathrm{A} \& \mathrm{~B}) \leftrightarrow \mathrm{OA} \& \mathrm{OB}$

De este axioma se deduce, por transitividad,

$\mathrm{OA} \leftrightarrow \mathrm{O}(\mathrm{A} \vee \mathrm{B}) \&(\mathrm{~A} v-\mathrm{B})$

De este último se sigue:

$\mathrm{OA} \rightarrow \mathrm{O}(\mathrm{A} v \mathrm{~B})$

A través de un proceso similar inferimos:

$\mathrm{OA} \rightarrow \mathrm{O}(-\mathrm{A} v \mathrm{~B})$

que de acuerdo con el propio concepto de implicación equivale a

$\mathrm{OA} \rightarrow \mathrm{O}(\mathrm{A} \rightarrow \mathrm{B})$

Esto es, si hacer "p" está prohibido, al hacer "p" nos comprometemos a hacer cualquier otra cosa, lo cual parece que intuitivamente contradice la noción de compromiso formalizada como $\mathrm{O}(\mathrm{A} \rightarrow \mathrm{B})$. $\mathrm{OA} \rightarrow \mathrm{O}(\mathrm{A} \rightarrow \mathrm{B})$ es la fórmula deóntica análoga a la que representa en lógica formal una de las paradojas de la implicación estricta, según la cual una proposición falsa implica cualquier otra proposición. Pero la paradoja deóntica resulta de mayor relevancia, porque el hecho de que "p" sea una proposición falsa no obliga ni a aceptarla ni a aceptar sus consecuencias, mientras que podemos realizar actos prohibidos que según el SDL nos colocan en la absurda situación de deber realizar cualquier otro acto. Es así como se puede llegar a otra para- 
doja derivada de la fórmula del compromiso, la paradoja de los imperativos contrarios al deber. Reflexionemos sobre la siguiente cadena deductiva:

(1) Debe ser el caso que socorramos llevándolo al hospital a todo accidentado grave que encontremos

(2) Debe ser el caso que si cumplimos la norma (1) ignoremos las señales de tráfico con tal de llegar rápido al hospital

(3) Si no cumplimos (1), debemos no ignorar las señales de tráfico

(4) No cumplimos (1)

Podemos expresar formalmente estos enunciados utilizando " $p$ " para "socorremos llevándolo al hospital a todo accidentado grave que encontramos", y utilizando "q" para "ignoramos las señales de tráfico con tal de llegar rápido al hospital":

(1) $\mathrm{Op}$

(2) $\mathrm{O}(\mathrm{p} \rightarrow \mathrm{q})$

(3) $-\mathrm{p} \rightarrow \mathrm{O}-\mathrm{q}$

(4) $-\mathrm{p}$

(3) y (4) implican, por modus ponens, "O-q". Y, por otro lado, de la cadena completa puede deducirse también "Oq", ya que en el SDL "Op \& $\mathrm{O}(\mathrm{p} \rightarrow \mathrm{q}) \rightarrow \mathrm{Oq}$ ” es una verdad lógica (es, en palabras de von Wright, un complejo molecular válido por razones puramente formales, aunque no sea la aplicación de un esquema válido para cualquier oración, deóntica o no).

Como "Oq" y "O-q" son contradictorios, estamos ante una paradoja, la paradoja de los imperativos contrarios al deber, que a juicio de von Wright es decisiva para demostrar por qué falla su SDL. En él, si “Op” expresa un deber primario, "O(-p $\rightarrow$ q)" no sirve como formalización de un imperativo contrario al deber para el supuesto de que incumplamos el deber primario "Op". Siguiendo los axiomas del SDL, cualquiera que sea el estado de cosas que "q" describa, debemos hacer "q" si incumplimos el deber de hacer " $p$ ", lo cual choca con la noción de "imperativos contrarios al deber", que obligan a realizar un determinado acto o conjunto de actos - no cualquier cosa - si dejamos de cumplir el deber primario.

Von Wright analizó la fórmula alternativa para la noción de compromiso “-p $\rightarrow$ Oq", entendida como hipotético imperativo contrario al deber condicionado al incumplimiento de "Op" (von Wright, 1982). No obstante, “-p $\rightarrow$ Oq" es ambigua porque se puede interpretar en sentido descriptivo y en sentido prescriptivo. En el primer caso, “-p $\rightarrow$ Oq” constata simplemente el hecho de que, si no es que "p", existe una norma según la cual debe ser que "q", y por lo tanto no es en sí misma una norma condicional. En el segundo caso, "-p $\rightarrow$ Oq" es una expresión que carece de sentido en el discurso significativo, puesto que se compondría de un elemento descriptivo y de un elemento prescriptivo enlazados mediante una conectiva veritativa. Sólo 
elípticamente podría considerarse que "-p $\rightarrow$ Oq" alude a cómo las cosas deberían ser. Incluiría implícitamente un operador deóntico de segundo orden, por lo que realmente la expresión sería " $\mathrm{O}(\mathrm{p} \rightarrow \mathrm{Oq})$ ", con lo que volveríamos a encontrarnos con los mismos problemas que nos hicieron desechar " $\mathrm{O}(\mathrm{p} \rightarrow \mathrm{q})$ ".

\section{La evolución del SDL: las lógicas deónticas de von Wright}

\subsection{La lógica deóntica de Norm and Action}

La aportación más conocida (y reconocida) de von Wright a la lógica deóntica y a la teoría de la acción es posiblemente Norm and Action (1963), libro además muy influyente en la teoría y filosofía jurídica de las últimas decadas, pero en el que sin embargo no aclara su opción ontológica. Las normas, dirá entonces von Wright, no son entidades extralingüísticas, simples regularidades sociales de comportamiento; pero tampoco entidades lingüísticas. Von Wright no afirma claramente ni que sean enunciados lingüísticos (situados, por consiguiente, a un nivel sintáctico), ni que sean proposiciones lingüísticas (a un nivel semántico), ni que sean actos de enunciación lingüística (a un nivel pragmático).

Así, además de descartar que las normas sean entidades extralingüísticas ("las normas dependen del lenguaje [...]. Su existencia presupone necesariamente el uso del lenguaje"), von Wright también parece negar que sean enunciados deónticos ("deberemos distinguir entre la norma y la formulación normativa. La formulación normativa es el signo o símbolo (las palabras) usadas al enunciar (formular) la norma"), que sean proposiciones deónticas ("es evidente que a algunas normas no se les puede dar el nombre de 'proposiciones' [...]. Las normas no tienen por qué llamarse ni la referencia ni incluso el sentido o significado de la correspondiente formulación normativa") y que sean enunciaciones deónticas de enunciados ("la norma es algo distinto del hecho de dar a conocer a los sujetos normativos su carácter, contenido y condiciones de aplicación, lo cual es un eslabón esencial en el (o parte del) proceso a través del cual la norma se origina o cobra existencia (ser), pero no es la norma en sí misma") (von Wright, 1963; vid. Hernández Marín, 1986).

En el contexto de esta indefinición ontológica von Wright presenta un sistema de modalidades deónticas diádicas con el objetivo de superar la unilateralidad argumental de los operadores monádicos del SDL. Con los operadores diádicos se expresan, implícita o explícitamente, relaciones entre dos argumentos que constituían el antecedente y el consecuente de la implicación normativa, de la implicación deóntica. 
En el sistema diádico, las acciones dejan de ser obligatorias en sí mismas, y es preciso determinar en qué condiciones lo son, en qué universo normativo o fáctico lo son. Este sistema diádico se componía de tres estratos: (i) la lógica proposicional tradicional, basada en el estudio formal de las expresiones p, q,...; (ii) la lógica del cambio, basada en el estudio formal de las expresiones $\mathrm{T}$, en la que el suceso descrito por "pTq" es una transformación de un estado inicial de cosas descrito por " $p$ " a un estado final de cosas descrito por "q"; (iii) la lógica de la acción, basada en el estudio formal de las expresiones df, en la que "d(-pTp)" significa que un agente, en una determinada ocasión, provoca el estado de cosas descrito por "p", inexistente hasta entonces; y en la que " $\mathrm{f}(-\mathrm{pTp})$ " significa que un agente, en una determinada ocasión, se abstiene de provocar el estado de cosas descrito por "p".

La teoría lógica de la acción condicionada constituía una extensión de la lógica de la acción. Introducía el símbolo / , de forma que la expresión "/ elemental de "(pTp)/(qTq)" describiera una acción genérica que es ejecutada por un agente de forma que en una determinada ocasión en la que el estado de cosas descrito por "q" se da y permanece independientemente de la acción, el agente impide que desaparezca el estado descrito por " $p$ ". "O(pTp)/(qTq)" es un mandato, cuyo contenido es la acción descrita por "d(pTp)", y cuya condición de aplicación es el cambio descrito por "pTp \& qTq".

En su artículo A New System of Deontic Logic (1964), von Wright perfecciona su sistema diádico interpretando la expresión atómica " $\mathrm{O}(\mathrm{p} / \mathrm{q})$ " como "se debe hacer que "p" cuando "q"" o "se debe hacer que "p" si es el caso que "q"". "p" y "q" describen posibles estados de cosas. Cuando el mundo es como "q" lo describe, entonces el mundo debe ser como " $p$ " lo describe. De análoga forma, “ $\mathrm{O}(\mathrm{p} / \mathrm{p})$ ” significa que el mundo es como debe ser, por lo que implica el deber de que el estado de cosas en cuestión no desaparezca; y "O(p/-p)" significa que se debe hacer que "p" cuando no es el caso que "p", por lo que el estado de cosas en cuestión debe llegar a ser. Aunque las reglas de inferencia del nuevo sistema de lógica deóntica (NSDL) se heredan del SDL, los nuevos axiomas difieren de los antiguos como consecuencia de la introducción de operadores diádicos:

$$
\begin{aligned}
& \mathrm{N} 1-(\mathrm{O}[\mathrm{p} / \mathrm{q}] \& \mathrm{O}[-\mathrm{p} / \mathrm{q}]) \\
& \mathrm{N} 2 \mathrm{O}(\mathrm{p} \& \mathrm{q} / \mathrm{r})<-->\mathrm{O}(\mathrm{p} / \mathrm{r}) \& \mathrm{O}(\mathrm{q} / \mathrm{r}) \\
& \mathrm{N} 3 \mathrm{O}(\mathrm{p} / \mathrm{q} \text { v r })<-->\mathrm{O}(\mathrm{p} / \mathrm{q}) \& \mathrm{O}(\mathrm{p} / \mathrm{r})
\end{aligned}
$$

Si partimos de los axiomas o teoremas del SDL y sustituimos las expresiones atómicas $\mathrm{O}$ que hay en ellos por expresiones atómicas del tipo $\mathrm{O}(\mathrm{t})$ (en las que $\mathrm{t}$ representa una tautología formada por las variables $\mathrm{p}, \mathrm{q}, \mathrm{r}, \ldots \mathrm{y}$ las conectivas de verdad), las fórmulas obtenidas son teoremas del NSDL. 
“-(Op \& O-p)" se puede transformar en “-(O[p/t] \& O[-p/t])", y asimismo “O(p \& q) <--> Op \& Oq" se puede transformar en “ $\mathrm{O}(\mathrm{p} \&$ q $/ \mathrm{t})<-->\mathrm{O}(\mathrm{p} / \mathrm{t})$ $\& \mathrm{O}(\mathrm{q} / \mathrm{t})$ ". De estos dos teoremas se pueden inferir en el NSDL tantos otros como los que se obtienen en el SDL de las respectivas fórmulas citadas.

\subsection{La lógica deóntica condicional}

En 1968, von Wright escribe Deontic Logic and the Theory of Conditio$n s$, donde deja de considerar la lógica deóntica como directamente análoga a la lógica modal, y donde pasa a considerarla un apartado de la "lógica de las condiciones suficientes y necesarias", de tal forma que afirmar que algo debe ser equivale a afirmar que algo es condición necesaria de alguna otra cosa.

En este sistema de lógica condicional, la noción de condición necesaria se explica así: "la verdad de la proposición " $p$ " es condición necesaria de la verdad de la proposición "q"”. Su representación formal puede ser "Nc(p,q)" o "N(q --> p)".

En efecto, decir que "p" es condición necesaria de "q" significa que si “-p", entonces “-q", o, asimismo, que si “q", entonces necesariamente " $p$ ". En términos de condición necesaria, el operador deóntico " $\mathrm{O}$ ” puede ser definido así: “Op = Nc(p,I)”. Que algo debe ser el caso significa que la cosa en cuestión es una condición necesaria de otra determinada cosa (o estado de cosas) "I", que se presupone en el contexto. "I" no es una variable, sino una constante proposicional.

Por su parte, la noción de condición suficiente se explica así: "la verdad de la proposición que "p" es una condición suficiente de la verdad de la proposición que "q"). Su representación formal puede ser "Sc(p,q)" o "S(q $-->$ p)"

En efecto, decir que "p" es condición suficiente de "q" significa que si “-q", entonces “-p", o, asimismo, que si "p", entonces necesariamente "q". "Sc(p,q)" equivale a "Sc(-q,-p)", a "Nc(q,p)" y a "Nc(-p,-q)". En términos de condición suficiente, el operador deóntico "P" puede ser definido así: "Op = Nc(p,I)". Que algo debe ser el caso significa que la cosa en cuestión es una condición suficiente de otra determinada cosa (o estado de cosas) "I", que se presupone en el contexto.

\subsection{La lógica deóntica de los verbos de acción}

Sin arrepentirse de su concepción de la lógica deóntica como fragmento de la teoría lógica modal de las condiciones necesarias y suficientes, concepción que le había dirigido hacia un enfoque instrumentalista de la lógica de las normas, von Wright se centró pocos años después (Deontic Logic Revisited, 1973) en la distinción, hasta entonces poco estudiada, entre Sein-So- 
llen (deber ser) y Tun-Sollen (deber hacer), entre las normas que establecen que determinada cosa debe o puede o no debe ser el caso, y las normas que establecen que alguien debe o puede o no debe hacer determinada cosa.

Esta distinción provocaba una alternativa básica en relación con la cuestión de la naturaleza de la lógica deóntica. Von Wright resaltó que la única lógica deóntica construida a partir de la lógica de la acción se había fundado en interpretaciones de las normas como enunciados descriptivos que acompañan a los operadores deónticos ("es obligatorio que las cosas se den", "está permitido que las cosas se den", "está prohibido que las cosas se den"). Existiría entonces una lógica deóntica inexplorada, basada en la conjunción de operadores deónticos y verbos de acción, en la que las variables representarían esquemáticamente frases verbales ("es obligatorio hacer x", "está permitido hacer x", "está prohibido hacer x").

La distinción entre Sein-Sollen y Tun-Sollen es retomada y reformulada posteriormente por von Wright al diferenciar entre: (i) el "deber técnico" ("must"), conforme al cual las cosas deben ser hechas para que otras cosas se consigan, y que suele ser elíptico, suele referirse implícitamente a un fin que no se conseguirá si lo que debe (técnicamente) ser no es; (ii) el "deber deóntico" ("ought"), que procede directamente de una norma, y que es categórico, no es un medio sino un fin en sí mismo (von Wright, 1982).

\subsection{La lógica deóntica de acciones individuales}

En On the Logic of Norms and Actions (1981), von Wright cuestiona la idea de que los términos deónticos se refieren a categorías de acciones y no a acciones individuales, algo que decidió en Deontic Logic y que comenzó a matizar en Norm and Action. Y la relaciona con la supuesta interdefinibilidad de los operadores deónticos y la consiguiente imposibilidad de admitir normas contradictorias.

Una acción individual (act-individual) se puede esquematizar diciendo que el agente a hace "p" en la ocasión o. Para identificarla correctamente, no basta con concretar a y o, ya que un agente puede realizar más de una acción en una misma ocasión, por lo que la acción individual, por sí misma, no proporciona datos definitivos sobre su contenido; es necesario aludir a la acción genérica (act-category) "p". Por ello, en las categorías deónticas cuentan tanto las acciones individuales como las acciones genéricas. Si una acción genérica es obligatoria, está permitida, o está prohibida (la categoría deóntica aparece aquí como operador), la realización u omisión de la acción genérica por parte de un individuo presupone que la acción individual tiene la "propiedad" de ser obligatoria, de estar permitida o de estar prohibida (por el contrario, la categoría deóntica aparece aquí como predicado). 
Esta forma de ambivalencia de las categorías deónticas (una misma categoría deóntica se usa como operador cuando hace referencia a acciones genéricas, y como predicado cuando hace referencia a acciones individuales) provoca, a juicio de von Wright, importantes consecuencias. Predicar de una acción individual que está permitida debe significar que la acción se incluye dentro de una categoría de acciones genéricas permitidas. En este sentido, de la permisión de un determinado tipo de acciones genéricas podemos inferir la no-prohibición de tales acciones y la no-obligatoriedad de su omisión. Pero si concebimos las categorías deónticas como predicados de acciones individuales no es posible la interdefinibilidad: una misma acción individual puede a la vez ser obligatoria y estar prohibida. Por lo tanto, sólo si consideramos las categorías deónticas como operadores de acciones genéricas hay incompatibilidad entre la obligatoriedad y la prohibición de una misma categoría de acciones. Ni el principio de no contradicción ni la interdefinibilidad de los operadores deónticos se dan como tales en una lógica deóntica que no relacione acciones genéricas, sino acciones individuales.

\subsection{La lógica deóntica como legislación racional}

En Norms, Truth and Logic (1982), von Wright expone su posición prácticamente definitiva sobre el contenido, implicaciones y presuposiciones de la lógica deóntica. Concibe las leyes de la lógica deóntica como "principios de legislación racional", y utiliza como ficción (y, por consiguiente, sin adherirse a ella) la idea de que las normas expresan la voluntad de la autoridad legislativa soberana, de que las normas forman un sistema en tanto que proceden de una voluntad ordenadora cuyo criterio de racionalidad ha de consistir en el hecho de que los estados de cosas queridos por el legislador sean (o, al menos, puedan ser) lógicamente posibles.

Aunque, en rigor, no hay una lógica de las normas, del deber ser, porque las normas no son ni verdaderas ni falsas, von Wright sugiere ahora el estudio de una lógica normativa bajo la condición de presuponer que las normas se pueden juzgar según su racionalidad. Resulta así imprescindible analizar los requisitos de racionalidad que debe "satisfacer" una actividad nomothética ("norm-giving activity", actividad de "dar normas", de "poner normas").

Conceptos como el de coherencia normativa (autocoherencia de una norma y coherencia entre las normas) y como el de implicación normativa no se asumen como conceptos propiamente lógicos, sino como conceptos relativos a la racionalidad de la voluntad legisladora. Las tautologías de la lógica deóntica aparecen así como principios de legislación racional (praxeológica), y la actividad judicial de subsunción normativa no es vista 
ya como una inferencia lógico-normativa, sino como una labor creativa, como un acto nomothético.

En conclusión, las normas no son apofánticas, de ellas no se predica la verdad ni la falsedad, pero si atendemos al criterio de la racionalidad del legislador podemos dotar de significado lógico a la contradicción normativa y a la implicación normativa. Ahora bien, como resalta von Wright, contradicción normativa e implicación normativa son categorías propiamente lógicas, no ontológicas, son categorías que no se expresan en términos ontológicos de contradicción e implicación existencial. Los sistemas de lógica deóntica sólo son modelos ideales que no representan adecuadamente estructuras normativas existentes. "Si existen dos normas en conflicto, lo cual puede suceder, es preciso que el legislador modifique la legislación. El lógico no puede ayudarle" (von Wright, 1982, p. 136). Aunque no son verdaderas ni falsas, las normas pueden ser explicadas o justificadas, precisa el último von Wright, por ejemplo a través de la referencia teleológica al fín que teóricamente se consigue a través de su cumplimiento, con lo que inevitablemente desembocamos en un problema valorativo: "El fin es normalmente algo valorado como deseable o bueno por quien establece la norma, y también, si es posible, por sus destinatarios, así que se puede afirmar que la justificación teleológica de las normas hace normalmente referencia a valores" (von Wright, 2001, p. 391).

\section{Bibliografía}

Alchourrón, Carlos / Bulygin, Eugenio, Análisis lógico y derecho. Centro de estudios constitucionales, Madrid, 1991.

Conte, Amedeo G. / Hilpinen, Risto / Wright, Georg H. von (eds.), Deontische Logik und Semantik. Athenaion, Wiesbaden, 1977.

Conte, Amedeo G. / Alarcón Cabrera, Carlos, Deóntica de la validez. Tecnos, Madrid, 1995.

GonzÁlez Lagier, Daniel, Acción y norma en G. H. von Wright. Centro de estudios constitucionales, Madrid, 1995.

JoRgensen, Jorgen, Imperatives and Logic. "Erkenntnis", 7 (1937-1938), pp. 288296.

JoRgEnSEn, Jorgen, Imperativer og logik [Imperativos y lógica]. “Theoria”, 4, 1938, pp. 183-190. Traducción castellana de Carlos Alarcón Cabrera: Imperativos y lógica. "Isegoría", 20, 1999, pp. 207-215.

Hernández Marín, Rafael, Historia de la filosofía del derecho contemporánea. Tecnos, Madrid, 1986.

Kalinowski, Georges, Le problème de la vérité en morale et en droit. Vitte, Lyon, 1967.

KaLinowski, Georges, La logique des normes. PUF, París, 1972. Traducción castellana de Juan R. Capella: Lógica del discurso normativo. Tecnos, Madrid, 1975. 
Kelsen, Hans, Recht und Logik. "Forum", 12 (1965), pp. 421-425 y 495-500. Traducción castellana de Juan Carlos Gardella: Derecho y lógica. En: Kelsen, Hans / Klug, Ulrich, Normas jurídicas y análisis lógico. Centro de estudios constitucionales, Madrid, 1988, pp. 92-120.

KLug, Ulrich, Juristische Logik. Springer, Berlin, 1951. Traducción española de David García Bacca: Lógica jurídica. Universidad Central, Caracas, 1961.

Mazzarese, Tecla, Logica deontica e linguaggio giuridico. Cedam, Padua, 1989.

Ross, Alf, Imperatives and Logic. "Theoria”, 7 (1941), pp. 53-71. Reedición en: "Philosophy of Science", 11 (1944), pp. 30-46.

Wright, Georg H. von, Deontic Logic. "Mind”, 60 (1951), pp. 1-15.

Wright, Georg H. von, An Essay in Modal Logic. North-Holland, Amsterdam, 1951.

Wright, Georg H. von, A Note on Deontic Logic and Derived Obligation. "Mind", 65 (1956), pp. 507-509.

Wright, Georg H. von, On Conditionals. En: Wright, Georg H. von, Logical Studies. Routledge and Kegan Paul, Londres, 1957, pp. 127-165.

Wright, Georg H. von, On Promises. “Theoria”, 28 (1962), pp. 277-297.

Wright, Georg H. von, Norm and Action. Routledge and Kegan Paul, Londres, 1963. Traducción castellana de Pedro García Ferrero: Norma y acción. Tecnos, Madrid, 1970.

Wright, Georg H. von, The Variety of Goodness. Routledge and Kegan Paul, Londres, 1963.

Wright, Georg H. von, Practical Inference. "The Philosophical Review”, 72 (1963), pp. 159-179.

Wright, Georg H. von, A New System of Deontic Logic. "Danish Yearbook of Philosophy", 1 (1964), pp. 173-182. Reedición en: Hilpinen, Risto (ed.), Deontic Logic. Introductory and Systematic Readings. Reidel, Dordrecht, 1971, pp. 105-115.

Wright, Georg H. von, A Correction to a New System of Deontic Logic. "Danish Yearbook of Philosophy", 2 (1965), pp. 103-107. Reedición en: Hilpinen, Risto (ed.), Deontic Logic. Introductory and Systematic Readings. Reidel, Dordrecht, 1971, pp. 116-120.

Wright, Georg H. von, Deontic Logic and the General Theory of Conditions. "Crítica”, 2 (1968), pp. 3-25. Reedición en: Hilpinen, Risto (ed.), Deontic Logic. Introductory and Systematic Readings. Reidel, Dordrecht, 1971, pp. 159-177.

Wright, Georg H. von, An Essay in Deontic Logic and the General Theory of Action. North-Holland, Amsterdam, 1968. Traducción castellana de Ernesto Garzón Valdés: Un ensayo de lógica deóntica y la teoría general de la acción. Unam, México, 1976.

Wright, Georg H. von, On the Logic and Ontology of Norms. En: Davis, John W. (ed.), Philosophical Logic. Reidel, Dordrecht, 1969, pp. 89-107.

Wright, Georg H. von, On So-Called Practical Inference. "Acta sociologica", 15 (1972), pp. 39-53.

Wright, Georg H. von, Deontic Logic Revisited. "Rechstheorie", 4 (1973), pp. $37-$ 46. 
Wright, Georg H. von, On the Logic of Norms and Actions. En: Hilpinen, Risto (ed.), New Studies in Deontic Logic. Reidel, Dordrecht, 1981, pp. 3-35.

Wright, Georg H. von, Norms, Truth and Logic. En: Wright, Georg Henrik von, Practical Reason. Blackwell, Oxford, 1983, pp. 130-209. Traducción castellana de Carlos Alarcón Cabrera: Normas, verdad y lógica. Fontamara, México, 1997.

Wright, Georg H. von, Is and Ought. En: Bulygin, Eugenio / Gardies, Jean-Louis / Niiniluoto, Ilkka (eds.), Man, Laws, and Modern Forms of Life. Reidel, Dordrecht, 1985, pp. 263-281.

Wright, Georg H. von, On Conditional Obligation. "Särtryck ur juridisk tidskrift", 1 (1994-1995), pp. 1-7.

Wright, Georg H. von, Conditionality. En: Wright, Georg H. von, Six Essays in Philosophical Logic. Acta Philosophica Fennica, Helsinki, 1996.

Wright, Georg H. von, Ought to be-Ought to do. En: Garzón Valdés, Ernesto / Krawietz, Werner / von Wright, Georg H. / Zimmerling, Ruth (ed.), Normative Systems in Legal and Moral Theory. Festschrift for Carlos E. Alchourrón and Eugenio Bulygin. Duncker \& Humblot, Berlín, 1997, pp. 427-435.

Wright, Georg H. von, Valorar (o cómo hablar de lo que se debe callar). Nuevas bases para el emotivismo. Traducción castellana de Carlos Alarcón Cabrera. "Anuario de filosofía del derecho", 18 (2001), pp. 385-395. 